\title{
BioMedicine
}

Volume 12 | Issue 1

Article 4

2021

\section{Anti-Herpes Virus Activity Of Lactobacillus' Postbiotics}

Follow this and additional works at: https://www.biomedicinej.com/biomedicine

Part of the Life Sciences Commons, and the Medical Sciences Commons (c) (i)

This work is licensed under a Creative Commons Attribution 4.0 License.

\section{Recommended Citation}

Vilhelmova_Ilieva, Neli; Atanasov, Georgi; Simeonova, Lora; Dobreva, Lili; Mancheva, Kapka; Trepechova, Madlen; and Danova, Svetla (2021) "Anti-Herpes Virus Activity Of Lactobacillus' Postbiotics," BioMedicine: Vol. 12 : Iss. 1 , Article 4.

DOI: $10.37796 / 2211-8039.1277$

This Original Articles is brought to you for free and open access by BioMedicine. It has been accepted for inclusion in BioMedicine by an authorized editor of BioMedicine. 


\section{Anti-Herpes Virus Activity Of Lactobacillus' Postbiotics}

\section{Cover Page Footnote}

This work is financially supported by Grant KП-06-H 36/4 - Novel biological approaches for limiting infectious pathology in fish relevant to aquaculture through probiotics and their post-metabolites

(2019-2022), Bulgarian National Science Fund. The authors thank Assist. Prof. Ilina Amer, PhD at Sofia University for the thorough English read and revision of the manuscript. 


\title{
Anti-herpes virus activity of lactobacillus' postbiotics
}

\author{
Neli Vilhelmova-Ilieva ${ }^{a}$, Georgi Atanasov ${ }^{b}$, Lora Simeonova ${ }^{a}$, Lili Dobreva ${ }^{\text {, }}$ \\ Kapka Mancheva ${ }^{c}$, Madlena Trepechova ${ }^{a}$, Svetla Danova ${ }^{a, *}$ \\ a The Stephan Angeloff Institute of Microbiology - Bulgarian Academy of Sciences, Member of the Institut Pasteur International \\ Network, 26, Georgi Bonchev Str., 1113 Sofia, Bulgaria \\ ${ }^{\mathrm{b}}$ Institute of Biodiversity and Ecosystem Research - Bulgarian Academy of Sciences, 25, Georgi Bonchev, Str., 1113 Sofia, Bulgaria \\ ${ }^{\mathrm{c}}$ Institute of Biophysics and Biomedical Engineering, Bulgarian Academy of Sciences, 23, Georgi Bonchev, Str., 1113 Sofia, Bulgaria
}

\section{Abstract}

Background: Recently various lactic acid bacteria (LAB) and their post-metabolites have shown many positive effects on human and animal welfare. They appear to be beneficial in different disorders and pathological conditions, including in a broad-spectrum of infectious diseases.

Aim: To estimate in vitro the anti-herpes simplex activity of $\mathbf{1 1}$ postbiotic samples (lysates or cell-free supernatants CFS) produced during the fermentation of six candidate-probiotic Lactobacillus strains isolated from Bulgarian fermented milk products.

Materials and methods: In vitro protocols for assessment of different LAB samples on the Herpes simplex virus type 1 (HSV-1) replication, adsorption and virucidal effects were applied using MDBK cells.

Results: Four of the studied LAB samples expressed a statistically significant inhibition of the replication of HSV-1. The highest selective index (79.75) was calculated for the post-metabolites of Lactiplantibacillus plantarum, followed by a high molecular fraction of cell-derived fragments of Limosilactobacillus fermentum culture (S6) (SI = 34.63), CFS from late exponential L. plantarum $(S I=28.26)$ and neutralized CFS from $L$. fermentum $(S I=28.11)$. Pronounced virucidal activities of the postbiotics S1, S11 (L. fermentum), S3 (L. plantarum) and S6 (L. fermentum) were recorded, too. The inhibitory effect of the majority of the samples on the stage of adsorption of the virus to MDBK cells was remarkable. In addition, almost all of the postbiotics exerted a protective effect on healthy cells and significantly reduced viral yield at subsequent infection.

Conclusion: Pre-selected Lactobacillus strains demonstrated strain-specific effects against HSV-1. These postbiotics influence different stages of viral infection in cell cultures and their promising characteristics are currently evaluated.

Keywords: Antiviral activity, Herpes simplex virus type 1, Lactobacillus probiotics, Postbiotics

\section{Introduction}

$\mathrm{H}$ erpes simplex virus type 1 (HSV-1) infection is a widespread viral disease in the human population with more than $90 \%$ of the individuals being seropositive to the pathogen [1,2]. The virus is transmitted via close contact with a carrier, whether the person be asymptomatic or with the typical manifestation. After a primary infection acquired usually in the early childhood, the causative agent is translocated through the peripheral sensory nerves to the cranial nerve ganglion, where it establishes a lifelong latent persistence [3]. When exposed to different types of stimulation (temperature variation, prolonged exposure to sunlight, psychological stress, physical overload, or other active contagious diseases in the body, etc.), the latent virus can be reactivated and cause a recurrent disease. Herpes simplex virus (HSV) type 1 causes mainly symptoms affecting the mouth, throat, lips, eyes and the central nervous system but can also affect various areas of the skin. Recently incidences of genital herpes caused by HSV-1, as a result of transmission through oral contact in this area, have been reported [4-6]. Severe herpes-related conditions include encephalitis, meningitis, neonatal herpes $[7,8]$, as well

Received 16 July 2021; revised 13 September 2021; accepted 27 September 2021.

Available online 1 March 2022.

* Corresponding author at: Department of General Microbiology, The Stephan Angeloff Institute of Microbiology, Bulgarian Academy of Sciences, 26, Georgi Bonchev str., 1113 Sofia, Bulgaria. Fax: +359 28700109.

E-mail address: stdanova@yahoo.com (S. Danova). 
as disseminated infections in immunocompromised patients have been described [9-11].

The specific anti-herpes chemotherapy relies on nucleoside analogues which shorten the duration of symptoms and lead to faster healing of lesions. Currently, the most widely used drug is acyclovir (ACV), which is also the first selective inhibitor of HSV developed [12,13]. A disadvantage of these antivirals, both having been used as a first line and continuously applied medication in acute and chronic cases, respectively, is the relatively rapid formation of resistant mutants in patients with a compromised immune system who are particularly at risk. This naturally leads to the necessity to increase the therapeutic doses but unfortunately such a treatment quite often inevitably fails [14-17]. Therefore, new therapeutics, other than those targeted by nucleoside analogues, are needed to be enacted at different stages of the viral replication. Products of natural origin are being considered as possible candidates since they are better absorbed and tolerated by cells and their therapeutic doses are relatively low. Over the last few decades special attention has been paid to probiotics and their postmetabolites isolated from various dairy products [18]. Many of their biological activities, such as antimicrobial, antifungal, anti-tumor, immunomodulatory and still many others, have been proven [19]. Some probiotic postbiotics (the active metabolites produced during the fermentation) and/or parabiotics (cell-derived fragments) have shown antiviral activity. The postbiotics/parabiotics produced from live bacteria or released into environment after probiotic lysis may bring beneficial effects to the host [20]. These are presented by a wide range of effector molecules such as short chain fatty acids (SCFAs), bacteriocins, small molecules proteins/peptides, neurotransmitters, etc. [21] . Bacteriocins produced by Lactobacillus delbrueckii subsp. bulgaricus specifically inhibit the replication of influenza virus $\mathrm{A} /$ chicken/Germany, strain Weybridge $\left(\mathrm{H}_{7} \mathrm{~N}_{7}\right)$ and strain Rostock $\left(\mathrm{H}_{7} \mathrm{~N}_{1}\right)$ [22]. A significant decrease in influenza $\mathrm{H}_{1} \mathrm{~N}_{1}$ virus titers has also been observed in the treatment with Lactobacillus plantarum L-137 of infected mice, inducing a pro-inflammatory response [23]. When administering Lactobacillus rhamnosus GG decreased the incidence of respiratory viral infections [24] and a reduction in influenza-like symptoms was recorded with Lactobacillus acidophilus strain NCFM [25]. Consistent and broad in vitro anti-HIV activity has been reported for the carbocyclic lantibiotic Labyrinthopeptin A1 [26]. Glycerol monolaurate, a factor analogously secreted by Lactobacillus, has virucidal activity against enveloped viruses, including HIV-1
[27]. Inhibitory activity against murine norovirus (MNV) has also been investigated using a mixture of metabolites of Lactilactobacillus curvatus 1 [28]. Exopolysaccharides produced by lactic acid bacteria from genera Pediococcus, Leuconostoc and Lactobacillus show antiviral activity versus human Adenovirus type 5 [29]. Strains of L. plantarum and Lactobacillus amylovorus exhibit good inhibitory effects against Echovirus 7 (E7) and E19 [30]. Bifidobacterium longum and L. plantarum in combination with Chlorella soroquiniana in dairy products have exerted anti-rotavirus activity [31]. However, limited data exists on the mode of anti-Herpes simplex virus action of Lactobacillus-derived postmetabolites/parabiotics. The lack of therapy capable of eliminating herpes infections as well as the generation of resistant mutants in the current treatment approach requires the development of new agents with a mode of action alternative to nucleoside analogues. Having in mind the above stated objectives, 11 postbiotic samples obtained from 6 Lactobacillus strains with probiotic properties were investigated as anti-Herpes simplex virus type 1 agents at different stages of replication.

\section{Materials and methods}

\subsection{Lactobacilli and post-metabolites tested}

Lactic acid bacteria (LAB) in the present study are part of a laboratory collection of The Stephan Angeloff Institute of Microbiology, Bulgaria. They were pre-selected on the basis of previously estimated broad spectrum of anti-bacterial activity $[32,33]$. All strains were stored at $-20^{\circ} \mathrm{C}$ in MRS broth, supplemented with glycerol $(20 \% \mathrm{v} / \mathrm{v})$. Prior to the assay, all lactobacilli were pre-cultured twice in MRS broth (Merck, Germany) at $37^{\circ} \mathrm{C}$ for $24-48 \mathrm{~h}$.

A total of 11 samples (named S1-S11) (Table 1) derived from 6 Lactobacillus strains and a multibacterial formula of $8 \mathrm{LAB}$ strains were assessed for anti-HSV activity. Two vaginal strains Limosilactobacillus fermentum (L.f. S3) and Ligilactobacillus salivarius (L.s. 1), four Lactiplantibacillus plantarum (L.pl.) strains isolated from Bulgarian fermented milk products such as home-made sample of a yogurtlike product "katak" [34] - L.pl. L3 and L14 and from artisanal green cheese (produced only in the village Tcherni vit, Bulgaria) - strains L. pl 3 ZS and 4 ZS [33].

Four of the tested samples were filtered acid cellfree supernatants (aCFS) from exponential $(24 \mathrm{~h})$ cultures of the strains L. pl. L3 (sample S1); L. pl. L14 (S2), L. pl. ZS3 (S3) and L. pl. ZS4 (S4) in MRS broth (Merck, Germany). The other samples were 
Table 1. LAB samples tested in the present work.

\begin{tabular}{|c|c|c|}
\hline Samples & Tested strains & Description of the samples \\
\hline S1 & L. plantarum L3 & Acid CFS from exponential $\left(24 \mathrm{~h}\right.$ ) cultures in MRS broth (Merck, Germany) at $37^{\circ} \mathrm{C}$. \\
\hline S2 & L. plantarum L14 & \\
\hline S3 & L. plantarum L3ZS & \\
\hline S4 & L. plantarum L4ZS & \\
\hline S5 & L. fermentum S3 & $\begin{array}{l}\text { A low molecular mass fraction }<30,000 \text { Da obtained with centrifugation } \\
\text { (Hermle, Germany at } 5000 \mathrm{rpm}, 5 \mathrm{~min} \text { ) of aCFS from L. fermentum S3 culture in MRS, } \\
\text { using Amicone centrifuge tube, with cut-off membrane } 30,000 \mathrm{Da} \text {. }\end{array}$ \\
\hline S6 & L. fermentum S3 & $\begin{array}{l}\text { A high molecular mass fraction }>30,000 \text { Da obtained with centrifugation (Hermle, } \\
\text { Germany at } 5000 \mathrm{rpm}, 5 \mathrm{~min} \text { ) of aCFS from L. fermentum S3 culture in MRS, using } \\
\text { Amicone centrifuge tube, with cut-off membrane } 30,000 \mathrm{Da} \text {. }\end{array}$ \\
\hline S7 & Mixed LAB culture - Mix 8 & $\begin{array}{l}\text { A supernatant obtained by centrifugation at } 3000 \times g \text { from thermally destroyed } \\
\left(15 \text { min at } 110{ }^{\circ} \mathrm{C} \text { ) exponential mixed culture }- \text { Mix } 8 \text { (containing } 8 \text { Lactobacillus }\right. \\
\text { strains co-cultivated } 24 \mathrm{~h} \text { in MRS broth). }\end{array}$ \\
\hline S8 & L. salivarius $1 S$ & $\begin{array}{l}\text { A supernatant, obtained by centrifugation at } 3000 \times g \text { from ultra-sonicated } \\
\text { L. salivarius culture, cultivated } 24 \mathrm{~h} \text { in MRS broth at } 37^{\circ} \mathrm{C} \text {; }\end{array}$ \\
\hline S9 & L. fermentum S3 & $\begin{array}{l}\text { A neutralized cell-free supernatants ( } \mathrm{pH} 6.0) \text {, with } 5 \mathrm{M} \mathrm{NaOH} \text { from a } 24 \mathrm{~h} \text { - culture } \\
\text { of L. fermentum } \mathrm{S} 3 \text { in MRS broth }(\mathrm{pH} 6.5) \text {; }\end{array}$ \\
\hline S10 & L. fermentum S3 & $\begin{array}{l}\text { A supernatant, obtained by centrifugation at } 3000 \times g \text { from ultra- sonicated L. fermentum S3 } \\
\text { culture, cultivated } 24 \mathrm{~h} \text { in MRS broth at } 37^{\circ} \mathrm{C}\end{array}$ \\
\hline S11 & L. fermentum S3 & Filtered aCFS from exponential $(24 \mathrm{~h})$ cultures in MRS broth (Merck, Germany) at $37^{\circ} \mathrm{C}$ \\
\hline
\end{tabular}

different fractions from LAB postmetabolites in the same laboratory medium as follows: the sample S5 a low molecular mass fraction $<30,000 \mathrm{Da}$, obtained with centrifugation (Hermle, Germany at $5000 \mathrm{rpm}$, $5 \mathrm{~min}$ ) of a CFS of L. fermentum S3 culture, using Amicone centrifuge tube, with cut-off membrane 30,000 Da; the sample S6 - a high molecular mass fraction $>30,000 \mathrm{Da}$, obtained as the S5 sample from L. fermentum S3; sample S7 - the supernatant obtained by centrifugation at $3000 \times g$ from thermally destroyed $\left(15 \mathrm{~min}\right.$ at $\left.110^{\circ} \mathrm{C}\right)$ exponential co-culture Mix 8 (containing 8 Lactobacillus strain co-cultivated $24 \mathrm{~h}$ in MRS broth); the sample S8 - a supernatant, obtained by centrifugation at $3000 \times g$ from ultrasonicated $L$. salivarius 1 culture, cultivated $24 \mathrm{~h}$ in MRS broth at $37{ }^{\circ} \mathrm{C}$; S9 - neutralized with $5 \mathrm{M}$ $\mathrm{NaOH}$ cell-free supernatants ( $\mathrm{pH}$ 6.0) from a $24 \mathrm{~h}$ culture of L. fermentum S3- in MRS broth ( $\mathrm{pH} 6.5$ ); the sample S10 - a supernatant, obtained by centrifugation at $3000 \times g$ from ultra-sonicated $L$. fermentum S3 culture, cultivated $24 \mathrm{~h}$ in MRS broth at $37{ }^{\circ} \mathrm{C}$ and the sample S11 - a CFS from $24 \mathrm{~h} L$. fermentum S3 culture in MRS broth. All samples were filter sterilized $(0.22 \mu \mathrm{m})$ and stored at $-20{ }^{\circ} \mathrm{C}$ prior to the experiments.

The Bradford reagent (Sigma) with Coomassie dye-binding assays was used for protein quantification $(\mathrm{mg} / \mathrm{ml})$ of all samples, according to instructions of the manufacturer.

\subsection{Virus and cells}

Madin-Darby bovine kidney (MDBK) cells were obtained from National Bank for Industrial
Microorganisms and Cell Cultures, Sofia, Bulgaria. The cell lines were grown in DMEM medium containing $10 \% \mathrm{v} / \mathrm{v}$ fetal bovine serum (Gibco BRL, USA), supplemented with $10 \mathrm{mM}$ HEPES buffer (Merck, Germany) and antibiotics (penicillin $100 \mathrm{IU} /$ $\mathrm{ml}$, streptomycin $100 \mu \mathrm{g} / \mathrm{ml}$ ) in $\mathrm{CO}_{2}$ incubator (HERA cell 150, Heraeus, Germany) at $37{ }^{\circ} \mathrm{C} / 5 \%$ $\mathrm{CO}_{2}$.

Herpes simplex virus type 1, Victoria strain (HSV1) was received from Prof. S. Dundarov, National Center of Infectious and Parasitic Diseases, Sofia. Virus was replicated in monolayer MDBK cells in a maintenance solution DMEM Gibco BRL, Paisley, Scotland, UK, plus $0.5 \%$ fetal bovine serum Gibco BRL, Scotland, UK. Infectious titer of stock virus was $10^{7.5} \mathrm{CCID}_{50} / \mathrm{ml}$.

\subsection{Cytotoxicity of LAB samples}

Confluent monolayer cell culture in a 96-well plates (Costar ${ }^{\circledR}$, Corning Inc., Kennebunk, ME, USA) was treated with $0.1 \mathrm{ml} /$ well-containing a maintenance medium containing no (untreated control)/or decreasing concentrations of the tested products. Cells were incubated at $37{ }^{\circ} \mathrm{C}$ and $5 \% \mathrm{CO}_{2}$ for $48 \mathrm{~h}$. After microscopic evaluation, the medium containing the test compound was removed; cells were washed stained with neutral red and then incubated at $37{ }^{\circ} \mathrm{C}$ for $3 \mathrm{~h}$. After the incubation, the neutral red dye was removed; the cells were washed with PBS, and $0.15 \mathrm{ml} /$ well desorb solution $(1 \%$ glacial acetic acid and $49 \%$ ethanol in distilled water) was added. The optical density (OD) of each well was read at $540 \mathrm{~nm}$ in a microplate reader 
(Biotek Organon, West Chester, PA, USA). The 50\% cytotoxic concentration $\left(\mathrm{CC}_{50}\right)$ was defined as the material concentration that reduced the cell viability by $50 \%$ when compared to untreated control. Each sample was tested in triplicate with four cell culture wells per test sample.

The maximum tolerable concentration (MTC) of the products, which is the concentration at which they do not affect the cell monolayer and it looks like the cells in the control (untreated with extract) was also determined.

\subsection{Antiviral activity}

Cytopathic effect (CPE) inhibition test was used for assessment of antiviral activity of the extracts. Confluent cell monolayer in 96-well plates infected with 100 -cell culture infectious dose $50 \%\left(\mathrm{CCID}_{50}\right)$ in $0.1 \mathrm{ml}$ (HSV-1). After $60 \mathrm{~min}$ of virus adsorption, each of the products was added in various concentrations and cells were incubated for $48 \mathrm{~h}$ at $37{ }^{\circ} \mathrm{C}$. The cytopathic effect was determined using a neutral red uptake assay and the percentage of CPE inhibition for each concentration of the test sample was calculated using the following formula:

$$
\begin{aligned}
\% \mathrm{CPE} & =\left[\mathrm{OD}_{\text {test sample }}-\mathrm{OD}_{\text {virus control }}\right] /\left[\mathrm{OD}_{\text {toxicity }}\right. \\
\text { control } & \left.-\mathrm{OD}_{\text {virus control }}\right] \times 100
\end{aligned}
$$

where $\mathrm{OD}_{\text {test sample }}$ is the mean value of the ODs of the wells inoculated with virus and treated with the test sample in the respective concentration, $\mathrm{OD}_{\text {virus }}$ control is the mean value of the ODs of the virus control wells (with no compound in the medium) and $\mathrm{OD}_{\text {toxicity control }}$ is the mean value of the ODs of the wells not inoculated with virus but treated with the corresponding concentration of the test sample. The $50 \%$ inhibitory concentration $\left(\mathrm{IC}_{50}\right)$ was defined as the concentration of the material that inhibited $50 \%$ of viral replication when compared to the virus control. The selectivity index (SI) was calculated from the ratio $\mathrm{CC}_{50} / \mathrm{IC}_{50}$.

\subsection{Virucidal assay}

Contact samples of $1 \mathrm{ml}$ containing HSV-1 $\left(10^{4}\right.$ $\left.\mathrm{CCID}_{50}\right)$, as well as tested compound in its maximum tolerable concentration in a 1:1 ratio was stored at room temperature for different time intervals $(15,30,60,90$ and $120 \mathrm{~min})$. Then, the residual infectious virus content in each sample was determined by the end-point dilution method and $\Delta \operatorname{lgs}$ as compared to the untreated controls were evaluated.

\subsection{Virus attachment}

Twenty four well cell culture plates containing monolayer of MDBK cells were pre-chilled at $4{ }^{\circ} \mathrm{C}$ and were inoculated with $10^{4} \mathrm{CCID}_{50}$ of HSV-1 for adsorption at $4{ }^{\circ} \mathrm{C}$ and treated in parallel with MTC of the extract. At various intervals (15, 30, 45 and $60 \mathrm{~min}$ ) cells were washed with PBS in order to remove both the compound and the unattached virus, then overlaid with maintenance medium and incubated at $37^{\circ} \mathrm{C}$ for $24 \mathrm{~h}$. Following triple freezing and thawing the infectious virus, titer of each sample was determined by the end-point dilution method. Each sample was prepared in triplicate.

\subsection{Pre-treatment of $M D B K$ cells}

Monolayers of MDBK cells pre-grown into 24-well cell culture plates (CELLSTAR, Greiner Bio-One) $\left(2 \times 10^{6}\right.$ cells per well) were treated for $15,30,60,90$ and $120 \mathrm{~min}$ at concentration of MTC of the extract in the maintenance medium ( $1 \mathrm{ml}$ per well). The extract was then removed and the cells were washed with phosphate-buffered saline (PBS) and inoculated with HSV-1 (1000 CCID 50 in $1 \mathrm{ml}$ per well). After $60 \mathrm{~min}$ of absorption, the non-absorbed virus was removed and the cells were covered with maintenance medium. The culture plates were incubated at $37^{\circ} \mathrm{C}$ for $24 \mathrm{~h}$ and, after triple freezing and thawing, the infectious viral titers were determined by the end-point dilution method. $\Delta$ lgs were evaluated compared to viral control (untreated with compounds).

Table 2. In vitro assessment of cytotoxicity and antiviral activity of $L A B$ post-metabolites.

\begin{tabular}{llllll}
\hline \multirow{2}{*}{$\begin{array}{l}\text { Tested } \\
\text { samples }\end{array}$} & \multicolumn{2}{l}{ Cytotoxicity $(\mu \mathrm{g} / \mathrm{ml})$} & & \multicolumn{2}{l}{ Antiviral activity } \\
\cline { 2 - 3 } \cline { 5 - 6 } & $\mathrm{CC}_{50}$ & $\mathrm{MTC}$ & & $\mathrm{IC}_{50}(\mu \mathrm{g} / \mathrm{ml})$ & $\mathrm{SI}$ \\
\hline S1 & $131.7 \pm 5.34^{* * *}$ & 2.1 & & $0.8 \pm 0.04^{* * *}$ & 79.75 \\
S2 & $12.6 \pm 1.54^{* * *}$ & 0.6 & & $1.85 \pm 0.06^{* * *}$ & 3.51 \\
S3 & $13.3 \pm 0.54^{* * *}$ & 2.0 & & $3.07 \pm 0.21^{* * *}$ & 2.15 \\
S4 & $13.1 \pm 1.85^{* * *}$ & 0.6 & & $0.23 \pm 0.009^{* *}$ & 28.26 \\
S5 & $118.7 \pm 3.98^{* * *}$ & 6.6 & & - & - \\
S6 & $128.0 \pm 3.43^{* * *}$ & 1.8 & & $2.05 \pm 0.13^{* * *}$ & 34.63 \\
S7 & $253.4 \pm 8.21^{* *}$ & 12.3 & - & - \\
S8 & $12.8 \pm 2.12^{* * *}$ & 0.6 & - & - \\
S9 & $115.8 \pm 4.24^{* * *}$ & 1.9 & & $1.0 \pm 0.05^{* * *}$ & 28.11 \\
S10 & $849.1 \pm 5.32^{* * *}$ & 120.0 & & $10.0 \pm 0.44^{* * *}$ & 1.5 \\
S11 & $127.5 \pm 6.64 * * *$ & 6.3 & & $6.22 \pm 0.52^{* * *}$ & 10.49 \\
MRS broth & - & 157.1 & - & - \\
ACV & $291.0 \pm 9.4$ & - & $0.33 \pm 0.03$ & 881.8 \\
\cline { 5 - 6 } & & & &
\end{tabular}

** $\mathrm{p}<0.001$, when comparing the value of each post-metabolite with ACV; Student's $t$-test.

${ }^{* * *} \mathrm{p}<0.0001$, when comparing the value of each post-metabolite with ACV; Student's $t$-test. 


\subsection{Statistical analyses}

Determination of standard deviation (SD) was done using the program Origin Pro 7.5. Student's ttest compared two groups of results. The final data sets were analyzed with the Graph Pad Prism 4 program.

\section{Results}

The cytotoxicity assessment of the eleven LAB samples (post-metabolites and cell-derived fragments) from 6 pre-selected Lactobacillus strains (Table 1) was performed to exclude any possible overlapping cytopathic effect of the samples and changes induced purely by the virus itself. The assay was performed on MDBK monolayer cell line (Table 2).

One of the tested LAB (sample S8, which is derived from 8 active strains) showed cytotoxicity comparable to ACV and five LABs (samples S1, S5, S6, S9 and S11) exhibited about two-fold higher toxicity than the reference nucleoside analogue. Four of the tested samples (S2, S3, S4 and S7) were about 20 times more toxic than ACV and only one of the products $(\mathrm{S} 10)$ showed $\mathrm{CC}_{50}$ values which is about 3 times higher than that of reference substance.

In order to discard a probable effect of cytotoxicity of the MRS medium used for LAB cultivation, we also assessed its influence on the monolayer of MDBK cells. The results showed no toxicity, even of the stock solution (Table 2). The maximum tolerated concentration of substances which does not induce visible changes in the cell monolayer was also determined.

The effect of LAB post-metabolites on viral replication in MDBK cells was evaluated, too (Table 2). Four of the tested samples possessed remarkable anti-herpesvirus activity. The highest selective index (79.75) and therefore the most pronounced effect on the internal replicative cycle of HSV-1 was determined for aCFS of L. plantarum L3 (named S1 sample). Although being established as the most potent among all the tested post-metabolites, its effect was 10 times weaker than that of ACV. Next in activity was sample S6 with a selective index of 34.63 , followed by the aCFS of L. plantarum L4ZS (S4 sample) and neutralized CFS of L. fermentum S3 (named S9) with almost identical selective indices, 28.26 and 28.11, respectively. These results clearly showed that an active metabolite different from lactic acid is probably produced during the fermentation. We observed weak anti-viral effect for S11 $(\mathrm{SI}=10.49)$ and insignificant activities for S2
Table 3. Virucidal activity against HSV-1 various of LAB postmetabolites/parabiotics.

\begin{tabular}{|c|c|c|c|c|c|}
\hline \multirow{2}{*}{$\begin{array}{l}\text { Tested } \\
\text { samples }\end{array}$} & \multicolumn{5}{|l|}{$\Delta \lg$} \\
\hline & $15 \mathrm{~min}$ & $30 \mathrm{~min}$ & $60 \mathrm{~min}$ & $90 \mathrm{~min}$ & $120 \mathrm{~min}$ \\
\hline S1 & 0.75 & 1.0 & 1.0 & 1.5 & 2.0 \\
\hline S2 & 0 & 0 & 1.0 & 1.0 & 1.0 \\
\hline S3 & 0.5 & 1.0 & 1.75 & 1.75 & 1.75 \\
\hline S4 & 0.25 & 0.25 & 1.0 & 1.0 & 1.5 \\
\hline S5 & 0 & 0 & 0.25 & 0.25 & 0.25 \\
\hline S6 & 0.25 & 0.5 & 1.5 & 1.5 & 1.75 \\
\hline S7 & 0.25 & 0.5 & 1.0 & 1.0 & 1.0 \\
\hline S8 & 0 & 0.5 & 1.25 & 1.25 & 1.5 \\
\hline S9 & 0.75 & 0.75 & 1.5 & 1.5 & 1.5 \\
\hline S10 & 0.25 & 0.25 & 0.25 & 0.25 & 0.25 \\
\hline S11 & 0.25 & 0.5 & 0.5 & 1.0 & 2.0 \\
\hline
\end{tabular}

$(\mathrm{SI}=3.51), \mathrm{S} 3(\mathrm{SI}=2.15)$ and $\mathrm{S} 10(\mathrm{SI}=1.5)$. Three of the tested samples -S5, S7 and S8 did not show any effect on the viral replicative cycle of HSV-1 (Table 2).

The pronounced activity of some of the post-metabolites against the intracellular replicative cycle of HSV-1 inspired us to analyze whether they have an effect on the extracellular virions of HSV-1. The results in Table 3 indicate that at $15 \mathrm{~min}$ of virus exposure none of the products shows any activity. At $30 \mathrm{~min}$ exposure only S1 and S3 exert some moderate activity, and S3 at $60 \mathrm{~min}$ exposure showed $\Delta \lg =1.75$, which is sustained until 120th min (the last studied time interval) as compared to virus control. Weak activity at $60 \mathrm{~min}$ was determined for S6, S7 and S9 with S7 and S9 showing no greater virucidal properties up to 120 th $\mathrm{min}$, while $\mathrm{S} 6$ at $120 \mathrm{~min}$ showed an activity of $\Delta \lg =1.75$. The strongest virucidal effect of all examined products was recorded for S1 and S11 at 120 min with $\Delta \lg =2$ compared to vehicle-treated group.

The effect of post-metabolites on the attachment of HSV-1 virions to susceptible MDBK cells is summarized in Table 4 . At 15 min of exposure none

Table 4. Effect of LAB post-metabolites on viral adsorption of HSV-1 on MDBK cells.

\begin{tabular}{lllll}
\hline $\begin{array}{l}\text { Tested } \\
\text { samples }\end{array}$ & $\Delta \mathrm{lg}$ & & & \\
\cline { 2 - 5 } & $15 \mathrm{~min}$ & $30 \mathrm{~min}$ & $45 \mathrm{~min}$ & $60 \mathrm{~min}$ \\
\hline S1 & 1.25 & 4.75 & 4.75 & 5.0 \\
S2 & 0.25 & 1.5 & 1.5 & 2.0 \\
S3 & 0.25 & 1.5 & 1.5 & 1.75 \\
S4 & 0 & 1.25 & 1.25 & 1.25 \\
S5 & 0 & 0.25 & 0.25 & 0.5 \\
S6 & 0 & 1.75 & 3.0 & 5.5 \\
S7 & 0 & 1.25 & 3.0 & 5.0 \\
S8 & 0 & 0.5 & 2.5 & 5.0 \\
S9 & 0.25 & 2.0 & 2.0 & 2.0 \\
S10 & 0.25 & 0.5 & 1.25 & 1.75 \\
S11 & 0 & 1.75 & 3.0 & 5.5 \\
\hline
\end{tabular}


of the products showed any effect on the stage of adsorption of the virus on the cell membrane. At the next time interval of 30 min S1 exerted remarkable activity of $\Delta \lg =4.75$. Other products showing virucidal activity at this time interval were S9 $(\Delta \lg =2.0), \mathrm{S} 6(\Delta \lg =1.75)$ and $\mathrm{S} 11(\Delta \lg =1.75)$. After 45 min of contact with the substances the most impressive effect was calculated for $S 1(\Delta \lg =4.75)$, S6, S8 and S11 $(\Delta \lg =3.0)$. S7 $(\Delta \lg =2.5)$ and S9 $(\Delta \lg =2.0)$. S2, S3 $(\Delta \lg =1.5)$ and $S 4, \mathrm{~S} 10(\Delta \lg =1.25)$ had low activity. At $60 \mathrm{~min}$ from the effect of the post-metabolites a statistically strong inhibitory effect on the adsorption stage of HSV-1 virions to sensitive MDBK cells was found for all tested products except for S5 and S4.

The most significant effect was demonstrated by S6, S11 $(\Delta \lg =5.5)$ and S1, S7, S8 $(\Delta \lg =5.0)$. The influence of S2, S9 $(\Delta \lg =2.0)$ and S3, S10 $(\Delta \lg =1.75)$ was also estimated as strong.

The protective effect of post-metabolites established on the stage of adsorption of viral particles to host cells, brought us to the idea to test the samples' behavior on uninfected MDBK cells when applied prior to viral infection (Table 5). As early as $15 \mathrm{~min}$ of incubation of the LAB samples with uninfected cells the $S 9(\Delta \lg =2.5), S 7$ and $S 10(\Delta \lg =1.75)$ significantly preserved the cells from subsequent herpes infections. At $30 \mathrm{~min}$ of treatment with probiotic post-metabolites all of them, except S5, exerted defensive effects to the cells. They varied for the individual products: S9 $(\Delta \lg =2.5)$; S2, S11 $(\Delta \lg =2.25) ; \mathrm{S} 6(\Delta \lg =2.0) ; \mathrm{S} 1, \mathrm{~S} 3, \mathrm{~S} 8, \mathrm{~S} 10$ $(\Delta \lg =1.75)$ and a moderate effect was expressed by $S 4, S 7(\Delta \lg =1.5)$. It was enhanced by increasing the exposure time and a clear protection was observed after 120 min of treatment with the products (except for S5, which did not show activity in any of the studied time intervals). The most significant were the protective properties shown by acid CFS from $L$.

Table 5. Pretreatment of MDBK cells with $L A B$ derived fragments or postmetabolites before HSV-1 infection.

\begin{tabular}{llllll}
\hline $\begin{array}{l}\text { Tested } \\
\text { samples }\end{array}$ & $\Delta \lg$ & & & & \\
\cline { 2 - 6 } & $15 \mathrm{~min}$ & $30 \mathrm{~min}$ & $60 \mathrm{~min}$ & $90 \mathrm{~min}$ & $120 \mathrm{~min}$ \\
\hline S1 & 1.0 & 1.75 & 2.0 & 2.5 & 3.5 \\
S2 & 0.5 & 2.25 & 2.25 & 2.5 & 3.0 \\
S3 & 0.25 & 1.75 & 1.75 & 2.0 & 2.0 \\
S4 & 0.25 & 1.5 & 2.0 & 2.25 & 3.5 \\
S5 & 0.25 & 0.25 & 0.25 & 0.5 & 0.5 \\
S6 & 0.5 & 2.0 & 2.25 & 2.75 & 3.5 \\
S7 & 1.5 & 1.5 & 1.5 & 2.0 & 2.0 \\
S8 & 1.75 & 1.75 & 2.0 & 2.75 & 3.25 \\
S9 & 2.5 & 2.5 & 2.5 & 2.5 & 3.0 \\
S10 & 1.75 & 1.75 & 1.75 & 2.0 & 2.0 \\
S11 & 0.5 & 2.25 & 2.25 & 2.5 & 3.0 \\
\hline
\end{tabular}

plantarum strains in MRS - S1, S4 $(\Delta \mathrm{lg}=3.5)$; followed by a combination of 8 pre-selected candidate probiotic strains - $S 8(\Delta \lg =3.25)$ and $S 2, S 6, S 11$ $(\Delta \lg =3.0)$. Values for S3, S7, S10 samples were evaluated as $\Delta \lg =2.0$ (Table 5 ).

\section{Discussion}

One of the milestone challenges in developing antiviral chemotherapeutic agents comes from the natural conjunction between the viral replicative mechanisms and the regular host cell processes. Thus, targets for effective antiviral drugs are those virus-specific structures and functions that determine viral replication but are not essential for the cells and host organism's normal activities.

The first stage that can be affected by any antiviral candidate is the time before the pathogen enters the cell, i.e. the studied samples act on extracellular virions. The reduction in the ability of virions to infect sensitive cells is based on the capacity of particular compounds to inactivate extracellular viral particles nonspecifically by denaturating their proteins and/ or causing structural changes in supercapsid lipids. Various mechanisms of action of probiotics in viral infections exist but are not fully characterized. Possibly the virucidal effect of the samples S1, S2, S3 and $S 4$ reported in Table 3 is mainly due to the detrimental effect of lactic acid produced during the fermentation in the aCFS we studied. A similar effect has been described by the teams of Tuyama et al., 2006 [35] and Conti et al., 2009 [36] against human simplex virus type 2 (HSV -2). The presence of such a non-specific interaction is also suggested by the lack of a virucidal effect upon exposure to neutralized CFS (in which lactic acid was eliminated with $\mathrm{NaOH}$ ). The probiotics may combat with pathogens through different barrier mechanisms. LABs appear to be a rich source of biologically active products with diverse structure and biological functions. This research suggests that the postmetabolites produced by selected Lactobacillus strains during the fermentation in MRS broth are able to inhibit HSV-1 infection of MDBK cells at different stages of the replicative cycle. Thus, different samples from acid and neutralized cellfree supernatants of exponential cultures in MRS broth and cells fragments have been estimated. Our hypothesis was that $\mathrm{LAB}$ are able to produce different active metabolites during the fermentation, able probably strain-specifically to inhibit virus replication/attachment or infection. Moreover, it has been shown that selected vaginal strains of Lactobacillus (Levilactobacillus brevis CD2, L. salivarius FV2, L. plantarum FV9) as well as their cell-free 
supernatants affect various steps of herpes simplex virus type 2 (HSV-2) replication in vitro [36]. Independent studies on antiviral properties of multiple probiotics and their derivatives on the replication of herpes simplex viruses have been conducted [37]. It has been shown that selected vaginal strains of Lactobacillus, as well as their cell-free supernatants affect various steps of herpes simplex virus type 2 (HSV-2) replication in vitro [36]. The bacterial extract of Lactobacillus brevis and fragments of its cell wall has demonstrated a dose-dependent inhibitory effect on HSV-2 proliferation [38].

Next, encouraged by the above-mentioned results, our questioning whether the probiotic samples can induce insusceptibility to viral infection by pre-treatment of uninfected cells found its answer. The obvious protective effect of the tested samples on intact cells observed could be explained by their bacteriocin content. Bacteriocin-like inhibitory substances (BLIS) can block the receptors on the host cell responsible for virus recognition and binding [39]. The defensive mechanism of pre-treatment of cells with metabolic products of the probiotic $L$. plantarum strain N4 against transmissible gastroenteritis Coronavirus has also been proven. The analyzed composition of metabolic products by GC-MS revealed that the major components were sugars [40]. Perhaps the content and action of similar constituents in the LAB samples we studied explain the remarkable prophylactic antiviral properties on healthy cells of almost all tested samples, especially S1, S2, S4, S6, S8, S9 and S11. They reduce subsequent viral infection with a decrease in viral titer by $\Delta \lg \geq 3$. Moreover, the effect was also significant, after the elimination of protective role of lactic acid produced, as it was shown for sample S9 containing nCFS. Concomitantly variants of produced post-metabolites (samples S5, S6, S9 and S11) and parabiotics (S10) derived from the pre-selected L. fermentum $3 \mathrm{~S}$ strain, were assessed for anti-HSV effects in vitro.

Mousavi et al. (2018) assume that the inhibition of the HSV-2 entry into cells occurs because viral particles are trapped by Lactobacillus crispatus [41]. The same team suggested the formation of L. crispatus protective biofilm on the cell surface that block HSV-2 receptors and prevent the virus from entering cells in the early stages of infection.

Intriguingly, our additional experiments with LAB post-metabolites found potential of samples in terms of inhibition of virus attachment and its subsequent entry and further infection-related events (Table 4).

It has been suggested that bacteriocins secreted by different strains of lactobacilli as positively charged compounds can be adsorbed on the viral capsid by electrostatic interaction, thereby inhibiting viral adsorption to the host cell [42]. The result of such an interaction may be the inhibition of viral adsorption reported by us, as well as the viral effect of some of the samples. The L. fermentum S3 strain was preliminarily evaluated as a putative BLIS-producing strain active against Gram (+) and Gram (-) bacteria (unpublished data). Therefore, we prepared different samples to visualize the activity of the obtained postbiotics - low molecular weight samples - S5 or $>30,000 \mathrm{Da}-\mathrm{S} 6$ and cells-free supernatants of spent cultures -S9 and S11). Thermal destructed cells from exponential culture of L. salivarius $1 \mathrm{~S}-$ the sample S8, shows a complete absence of antiviral activity, despite the previously proven bacteriocinogenic anti-Salmonella activity [33]. Probably the active proteinaceous compound produced by $L$. salivarius $1 \mathrm{~S}$ was completely destroyed by high temperature $\left(120^{\circ} \mathrm{C}\right)$.

Herpes viruses induce the expression of a large number of virus-specific enzymes in the infected cells. They mimic the action of functionally related cellular enzymes but differ in a number of biochemical characteristics such as molecular weight, dependence on certain cations, sensitivity to inhibitors, substrate specificity and many others. The most effective therapeutics are those that block the intracellular replicative cycle of the virus by attacking specific viral structures in the infected cell that are necessary for its reproduction.

In this study, the highest selective indices were calculated for samples S1, S4, S6, S9 and S11, which could indicate interruption in one or more important steps of the intracellular replication cycle of HSV-1. This effect is not likely solely as a result of the lactic acid content present in the samples. Sample S9 was also active lacking lactic acid by neutralization in CFS of the exponential culture of one candidate probiotic strain Lf. S3 (Table 2). Serkedzhieva et al. (2000) found that bacteriocin B1 from Lactobacillus delbrueckii inhibited certain stages of the intracellular replicative cycle of the virus [22]. Wachsman et al. (2003) show that inhibition of HSV replication by enterocin CRL35 occurs in the late stages of virus replication by preventing the synthesis of gamma protein-glycoprotein D (gD), a structural component of the HSV envelope that is essential for entry of the virus in the host cell [39]. In other studies, a non-protein component contained in the cell wall of Lactobacillus brevis also has the ability to reduce HSV-2 replication [38]. Our assays in accordance with other teams, prove an inhibitory effect on viral particles and viral replication of $L A B$ and their postmetabolites. However, the 
experiments conducted so far represent only the initial stage of this research. It is necessary further to establish in more details the exact chemical composition of postmetabolites, as well as the effect that each ingredient has on viral replicative cycle. Additional studies should be performed to determine the precise mechanism explaining the antiherpes effect observed in the studies.

\section{Conclusion}

All in all, tested Lactobacillus strains demonstrated a strain-specific effect against HSV-1. This study assesed the capacity of LABs postmetabolites/cellderived fragments to influence different stages of viral infection in cell cultures. Our in vitro achievements showed new aspects for widespread use of LABs and their postbiotics in the treatment of herpes infections. They could successfully shorten and limit existing herpes recurrence, disrupting both stages of virus replication and restricting the movement and passage of the virus from cell to cell. The protective effect they have on healthy cells is also extremely important protecting them to a significant extent from the entry of viral particles into them. These activities would make LABs and their post metabolites reliable future therapies for herpes infections. Despite the reported decrease in viral yield at different stages of viral cycle, the exact mechanism by which probiotics and their post-metabolites act has not been established so far. This opens a broad perspective in the development and application of probiotics as antiviral agents with a variety of additional biological activities and benefits for human health.

\section{Author contributions}

All authors worked on and discussed the results, thus contributed to the final version of the paper: Dobreva L. - LAB media and fermentations, Danova S. - conception of the work, selection of candidate-probiotic strains and preparation of LAB samples for assessment; Trepechova M. - growing and providing a cell line MDBK for conducted experiments; Vilhelmova-Ilieva N.- determination of the cytotoxicity of the studied post-metabolites and conducting antiviral experiments and manuscript design; reporting,. Simeonova L. - determination of viral titers and manuscript edition; Kostova $\mathrm{K}$. and Mancheva K.- calculation and presentation of the obtained results; Mancheva K. and G. Atanasov preparation of a literature review and critical revision of the article.

\section{Conflict of interest}

The authors declare that they have no conflict of interest whatsoever.

\section{Acknowledgments}

This work is financially supported by Grant КП-06-H 36/4 - "Novel biological approaches for limiting infectious pathology in fish relevant to aquaculture through probiotics and their post-metabolites" (2019-2022), Bulgarian National Science Fund.

The authors thank Assist. Prof. Ilina Amer, PhD at Sofia University for the thorough English proofreading and revision of the manuscript.

\section{References}

[1] Chaabane S, Harfouche M, Chemaitelly H, Schwarzer G, Abu-Raddad LJ. Herpes simplex virus type 1 epidemiology in the Middle East and North Africa: systematic review, meta-analyses, and meta-regressions. Sci Rep 2019;9(1):1136.

[2] Marchi S, Trombetta CM, Gasparini R, Temperton N, Montomoli E. Epidemiology of herpes simplex virus type 1 and 2 in Italy: a seroprevalence study from 2000 to 2014 . J Prev Med Hyg 2017;58(1):E27-33. Available from: https:// www.ncbi.nlm.nih.gov/pmc/articles/PMC5432775/. [Accessed 10 April 2021].

[3] James C, Harfouche M, Welton NJ, Turner KM, AbuRaddad LJ, Gottlieb SL, et al. Herpes simplex virus: global infection prevalence and incidence estimates. In: 2016. Bull world health organ. 2020;98(5):315-29.

[4] Ryder N, Jin F, McNulty AM, Grulich AE, Donovan B. Increasing role of herpes simplex virus type 1 in first-episode anogenital herpes in heterosexual women and younger men who have sex with men, 1992-2006. Sex Transm Infect 2009; 85(6):416-9.

[5] Mustafa M, Illzam EM, Muniandy RK, Sharifah AM, Nang MK, Ramesh B. Herpes simplex virus infections, Pathophysiology and Management. IOSR J Dent Sci 2016; 15(7):85-91.

[6] Ayoub HH, Chemaitelly H, Abu-Raddad LJ. Characterizing the transitioning epidemiology of herpes simplex virus type 1 in the USA: model-based predictions. BMC Med 2019;17(1): 57.

[7] Finger-Jardim F, Avila EC, da Hora VP, Goncalves CV, de Martinez AMB, Soares MA. Prevalence of herpes simplex virus types 1 and 2 at maternal and fetal sides of the placenta in asymptomatic pregnant women. Am J Reprod Immunol 2017;78(1).

[8] Avila EC, Finger-Jardim F, Goncalves CV, da Hora VP, Soares MA, Martinez AMB. High incidence of herpes simplex virus-1 in cord blood and placenta infection of women in southern Brazil. Rev Bras Ginecol Obstet 2020;42(1):5-11.

[9] McQuillan G, Kruszon-Moran D, Flagg EW, Paulose-Ram R. United States, 2015-2016. NCHS Data Brief 2018;(304):1-8.

[10] Zaki SR, Keating MK. Viral diseases. Pulmon Pathol 2018: 244-88.

[11] Looker KJ, Welton NJ, Sabin KM, Dalal S, Vickerman P, Turner KME, et al. Global and regional estimates of the contribution of herpes simplex virus type 2 infection to HIV incidence: a population attributable fraction analysis using published epidemiological data. Lancet Infect Dis 2020;20(2): 240-9.

[12] Elion GB, Furman PA, Fyfe JA, de Miranda P, Beauchamp L, Schaeffer HJ. Selectivity of action of an antiherpetic agent, 9- 
(2-hydroxyethoxymethyl) guanine. Proc Natl Acad Sci U S A 1977;74(12):5716-20.

[13] Elion GB. Mechanism of action and selectivity of acyclovir. Am J Med 1982;73(1a):7-13.

[14] Coen DM. General aspects of virus drug resistance with special reference to herpes simplex virus. J Antimicrob Chemother 1986;18(Suppl B):S1-10.

[15] Bacon TH, Boon RJ, Schultz M, Hodges-Savola C. Surveillance for antiviral-agent-resistant herpes simplex virus in the general population with recurrent herpes labialis. Antimicrob Agents Chemother 2002;46(9):3042-4.

[16] Bargiela D, Lyall H, Mewasingh L. Oral acyclovir suppression after neonatal herpes. N Engl J Med 2012;366(1):90-1.

[17] Jiang YC, Feng H, Lin YC, Guo XR. New strategies against drug resistance to herpes simplex virus. Int J Oral Sci 2016; $8(1): 1-6$.

[18] Salman JA-S, Mahmood NN, Abdulsattar BO, Abid HA. The effectiveness of probiotics against viral infections: a rapid review with focus on SARS-CoV-2 infection. Open Access Maced J Med Sci 2020;8(T1):496-508.

[19] Tiwari SK, Dicks LMT, Popov IV, Karaseva A, Ermakov AM, Suvorov A, et al. Probiotics at war against viruses: what is missing from the picture? Front Microbiol 2020;11:1877.

[20] Tsilingiri K, Rescigno M. Postbiotics: what else? Benef Microbes 2013;4(1):101-7.

[21] Teame T, Wang A, Xie M, Zhang Z, Yang Y, Ding Q, et al. Paraprobiotics and postbiotics of probiotic lactobacilli, their positive effects on the host and action mechanisms: a review. Front Nutr 2020;7(191).

[22] Serkedjieva J, Danova S, Ivanova I. Antiinfluenza virus activity of a bacteriocin produced by Lactobacillus delbrueckii. Appl Biochem Biotechnol 2000;88(1):285-98.

[23] Maeda N, Nakamura R, Hirose Y, Murosaki S, Yamamoto Y, Kase T, et al. Oral administration of heat-killed Lactobacillus plantarum L-137 enhances protection against influenza virus infection by stimulation of type I interferon production in mice. Int Immunopharmacol 2009;9(9):1122-5.

[24] Rautava S, Salminen S, Isolauri E. Specific probiotics in reducing the risk of acute infections in infancy-a randomised, double-blind, placebo-controlled study. Br J Nutr 2009;101(11):1722-6.

[25] Leyer GJ, Li S, Mubasher ME, Reifer C, Ouwehand AC. Probiotic effects on cold and influenza-like symptom incidence and duration in children. Pediatrics 2009;124(2):172-9.

[26] Ferir G, Petrova MI, Andrei G, Huskens D, Hoorelbeke B, Snoeck R, et al. The lantibiotic peptide labyrinthopeptin A1 demonstrates broad anti-HIV and anti-HSV activity with potential for microbicidal applications. PLoS One 2013;8(5): e64010. Available from: https://journals.plos.org/plosone/ article/figure?id10.1371/journal.pone.0064010.g001. [Accessed 5 April 2021].

[27] Welch JL, Xiang J, Okeoma CM, Schlievert PM, Stapleton JT. Glycerol monolaurate, an analogue to a factor secreted by Lactobacillus, is virucidal against enveloped viruses, including HIV-1. mBio 2020;11(3). e00686-20. Available from: https://pubmed.ncbi.nlm.nih.gov/32371599/. [Accessed 13 April 2021].

[28] Lange-Starke A, Petereit A, Truyen U, Braun PG, Fehlhaber K, Albert T. Antiviral potential of selected starter cultures, bacteriocins and D,L-Lactic acid. Food Environ Virol 2014;6(1):42-7.

[29] Biliavska L, Pankivska Y, Povnitsa O, Zagorodnya S. Antiviral activity of exopolysaccharides produced by lactic acid bacteria of the genera Pediococcus, Leuconostoc and Lactobacillus against human Adenovirus type 5. Medicina 2019;55(9): 519.

[30] Sunmola AA, Ogbole OO, Faleye TOC, Adetoye A, Adeniji JA, Ayeni FA. Antiviral potentials of Lactobacillus plantarum, Lactobacillus amylovorus, and Enterococcus hirae against selected Enterovirus. Folia Microbiol 2019;64(2): 257-64.

[31] Cantu-Bernal S, Dominguez-Gamez M, Medina-Peraza I Aros-Uzarraga E, Ontiveros N, Flores-Mendoza L, et al. Enhanced viability and anti-rotavirus effect of Bifidobacterium longum and Lactobacillus plantarum in combination with Chlorella sorokiniana in a dairy product. Front Microbiol 2020;11:875.

[32] Danova S. Biodiversity and probiotic potential of lactic acid bacteria from different ecological niches [DSc thesis]. Sofia, Bulgaria: BAS, The Stephan Angeloff Institute of microbiology; 2015.

[33] Dobreva L, Georgieva V, Georgieva S, Koprinarova M. AntiSalmonella activity of lactobacilli from different habitats. Bulg J Vet Med March 2022;25(1), (in press).

[34] Danova S, Nemska V, Tropcheva R. Chapter 18-Bulgarian yogurt-like product "katak". In: Shah Nagendra P, editor. Yogurt in health and disease prevention. 1st ed. USA: Academic Press; 2017. p. 307-29.

[35] Tuyama AC, Cheshenko N, Carlucci MJ, Li JH, Goldberg CL, Waller DP, et al. ACIDFORM inactivates herpes simplex virus and prevents genital herpes in a mouse model: optimal candidate for microbicide combinations. J Infect Dis 2006; 194(6):795-803.

[36] Conti C, Malacrino C, Mastromarino P. Inhibition of herpes simplex virus type 2 by vaginal lactobacilli. J Physiol Pharmacol 2009;60(Suppl 6):S19-26.

[37] Al Kassaa I. The antiviral activity of probiotic metabolites. In: New insights on antiviral probiotics: from research to applications. 1 ed. Springer Int. Publishing; 2017. p. 83-97.

[38] Mastromarino P, Cacciotti F, Masci A, Mosca L. Antiviral activity of Lactobacillus brevis towards herpes simplex virus type 2: role of cell wall associated components. Anaerobe 2011;17(6):334-6.

[39] Wachsman MB, Castilla V, Holgado APdR, Torres RAd, Sesma F, Coto CE. Enterocin CRL35 inhibits late stages of HSV-1 and HSV-2 replication in vitro. Antivir Res 2003;58(1): 17-24.

[40] Yang Y, Song H, Wang L, Dong W, Yang Z, Yuan P, et al. Antiviral effects of a probiotic metabolic products against transmissible gastroenteritis Coronavirus. J Pol Hist 2017; 5(3).

[41] Mousavi E, Makvandi M, Teimoori A, Ataei A, Ghafari S, Samarbaf-Zadeh A. Antiviral effects of Lactobacillus crispatus against HSV-2 in mammalian cell lines. J Chin Med Assoc 2018;81(3):262-7.

[42] Ly-Chatain MH, Moussaoui S, Vera A, Rigobello V, Demarigny Y. Antiviral effect of cationic compounds on bacteriophages. Front Microbiol 2013;4(46):1-6. 